\title{
Collection on reports of molecules linked to epithelial-mesenchymal transition in the process of treating metastasizing cancer: a narrative review
}

\author{
Yiyi Cai ${ }^{1,2 \#}$, Boyuan Wang ${ }^{1,2 \#} \wedge$, Bingying Li ${ }^{1,2 \#}$, Xintong Huang ${ }^{1,2 \#}$, Haoyue Guo ${ }^{1,2}$, Yu Liu ${ }^{1,2}$, Bin Chen ${ }^{1}$, \\ Sha Zhao ${ }^{1}$, Shengyu Wu ${ }^{1,2}$, Wei Li ${ }^{1}$, Lei Wang ${ }^{1}$, Keyi Jia ${ }^{1,2}$, Hao Wang ${ }^{1,2}$, Peixin Chen ${ }^{1,2}$, Minlin Jiang ${ }^{1,2}$, \\ Xuzhen Tang ${ }^{3}$, Hui $\mathrm{Qi}^{3}$, Chunlei Dai ${ }^{3}$, Junyan Ye ${ }^{1}$, Yayi $\mathrm{He}^{1}$ \\ ${ }^{1}$ Department of Medical Oncology, Shanghai Pulmonary Hospital, Tongji University Medical School Cancer Institute, Tongji University School \\ of Medicine, Shanghai, China; ${ }^{2}$ Medical School, Tongji University, Shanghai, China; ${ }^{3}$ Oncology and Immunology BU, Research Service Division, \\ WuXi Apptec, Shanghai, China \\ Contributions: (I) Conception and design: Y Cai, B Wang, B Li, X Huang, Y He; (II) Administrative support: Y He; (III) Provision of study materials \\ or patients: None; (IV) Collection and assembly of data: Y Cai, B Wang, B Li, X Huang, H Guo, Y Liu, B Chen, H Wang, P Chen, M Jiang, J Ye; \\ (V) Data analysis and interpretation: Y Cai, B Wang, B Li, X Huang, S Zhao, S Wu, W Li, L Wang, K Jia, X Tang, H Qi, C Dai; (VI) Manuscript \\ writing: All authors; (VII) Final approval of manuscript: All authors. \\ \#These authors contributed equally to this work. \\ Correspondence to: Yayi He. Department of Medical Oncology, Shanghai Pulmonary Hospital, Tongji University Medical School Cancer Institute, \\ Tongji University School of Medicine, Shanghai, China. Email: 2250601@qq.com.
}

\begin{abstract}
Epithelial-mesenchymal transition (EMT) is a morphological process in which epithelial cells transform into mesenchymal cells via a specific procedure. EMT plays an important role in the cancer invasion-metastasis cascade and the current treatment of metastatic cancer, influences the migration, polarity, and adhesion of tumor cells, promotes their migration, invasiveness, anti-apoptotic ability. It contributes to the changes of the tumor microenvironment and suppresses the sensitivity of tumor cells to chemotherapy, causing cancer metastasis and worse, hindering the control and therapy of it. This paper reviews the mechanisms, detection, and treatments of cancer metastasis that have been identified and applied to date, summarizes the EMT-related biological molecules, providing a reference for EMT-targeted research and therapy. As EMT is significant in the progress of tumor metastasis, it is meaningful for the therapy and control of metastatic cancer to understand the mechanism of EMT at the molecular level. We summarized the mechanisms, detection and therapeutic implications of EMT, listed the research progress of molecules like genes, miRNAs, signaling pathways in EMT. We also discussed the prospects of EMT-targeted treatment in cancer metastasis interventions and the challenges the treatment and researches are facing. The summary is conducive to the treatment and further research of EMT and metastatic cancer.
\end{abstract}

Keywords: Epithelial-mesenchymal transition (EMT); EMT-targeted treatment; metastasis; cancer; molecules

Submitted Oct 19, 2020. Accepted for publication Apr 12, 2021.

doi: $10.21037 / \mathrm{atm}-20-7002$

View this article at: http://dx.doi.org/10.21037/atm-20-7002

\footnotetext{
$\wedge$ ORCID: 0000-0001-5240-1285.
} 


\section{Introduction}

Cancer metastasis, which is the process by which precancerous lesions spread from primary tumors to distal organs, is the leading contributing factor to cancer lethality (1). Over $90 \%$ of cancer-related deaths are caused by distant metastasis. Recently, epithelial-mesenchymal transition (EMT)-targeted treatment has become a popular area of research. The metastasis process is reported to be influenced and regulated by various mechanisms, including EMT. EMT can be targeted to prevent cancer metastasis in the early stage or eliminate metastatic cells in the advanced stage. We present the following article in accordance with the Narrative Review reporting checklist (available at http:// dx.doi.org/10.21037/atm-20-7002).

\section{Introduction: metastasis in cancer}

Cancers share the same basic mechanism of cancer metastasis. In this paper, we examine cancer metastasis in the condition of adrenal cancer.

\section{Mechanisms of adrenal metastasis in cancer}

In 2011, Valastyan et al. reviewed the "seed and soil" hypothesis and put forward the invasion-metastasis cascade (2) whereby cancer cells detach from primary tumors and then move to distant organ sites via the vasculature. Cancer cells successfully extravasate into distant tissues through their parenchyma. The blood supply in the adrenal sinuses is abundant, and the reticular capillary network endothelium is beneficial to the adhesion of cancer cells. After blood vessels have formed, cancer cells proliferate to form metastasis.

Venous, arterial, and blood capillary systems are the principal processes of adrenal metastasis, and early lung cancer cells are likely to metastasize to the ipsilateral adrenal gland via the lymphatic system. The invasion of cancer cells in the bone stimulates the self-renewal capacity of tumor-initiating cells (TICs). The transcription factors (TFs), such as Twist, Snail, and c-Ets1, promote EMT and facilitate TICs. These factors boost early invasion and have self-renewal properties (3).

\section{Detection of adrenal metastasis}

The main methods for diagnosing metastases are computerized tomography (CT), magnetic resonance imaging (MRI), and positron emission tomography (PET) (4).
Usually, detection methods include both a CT and a B-ultrasonic examination, both of which are ultrasound imaging methods. The B-ultrasonic examination is convenient and acceptable. The negative sonogram is characterized by uneven echo distribution in the mass and is usually hypoechoic. However, it is difficult to determine whether a cancer is primary or metastatic due to the similarity of the results and the internal echo's low sensitivity. CT can be used to conduct a further examination. Small lesions that the B-ultrasound can barely detect can be found through CT, the localizations of which are more accurate than those of the B-ultrasound. In a CT examination, the results of a metastatic tumor and non-functional adenoma are significantly different, but it is difficult to differentiate them from non-functional sebaceous adenocarcinoma and pheochromocytoma. If necessary, a CT and B-ultrasound biopsy can be used for a histological examination, but it could induce traumas (5). PET scanning can image a primary tumor, which is useful for detecting an unknown primary cancer and detecting other small metastases. PET scans are sensitive and specific (6).

\section{Treatment of metastasis}

Treatments of metastases (Table 1) include surgical resection, interventional therapy, local ablation, immunotherapy, radiotherapy, and chemotherapy (10).

\section{EMT-targeted treatment-a promising treatment}

\section{Introduction of EMT}

EMT is a biological process whereby a special process turns epithelial cells into cells with an interstitial phenotype. It plays a vital role in developing embryonic tissue reconstruction, cancer metastasis, chronic inflammation, and multiple fibrosis diseases. A decrease embodies it in cell adhesion molecules' expression, the morphological characteristics in mesenchymal cells, and the transition from keratin cytoskeleton into vimentin cytoskeleton (11). Many articles in different fields targeting different types of cancer have noted that some genes have a unique effect in the process in EMT, including those in the Snail family, Twist, and c-Ets1. Some of these produce direct changes in the EMT process, while others act by changing how deoxyribonucleic acid (DNA) and protein bind. Thus, understanding the mechanism of EMT provides insights into targeted treatments for cancer. 


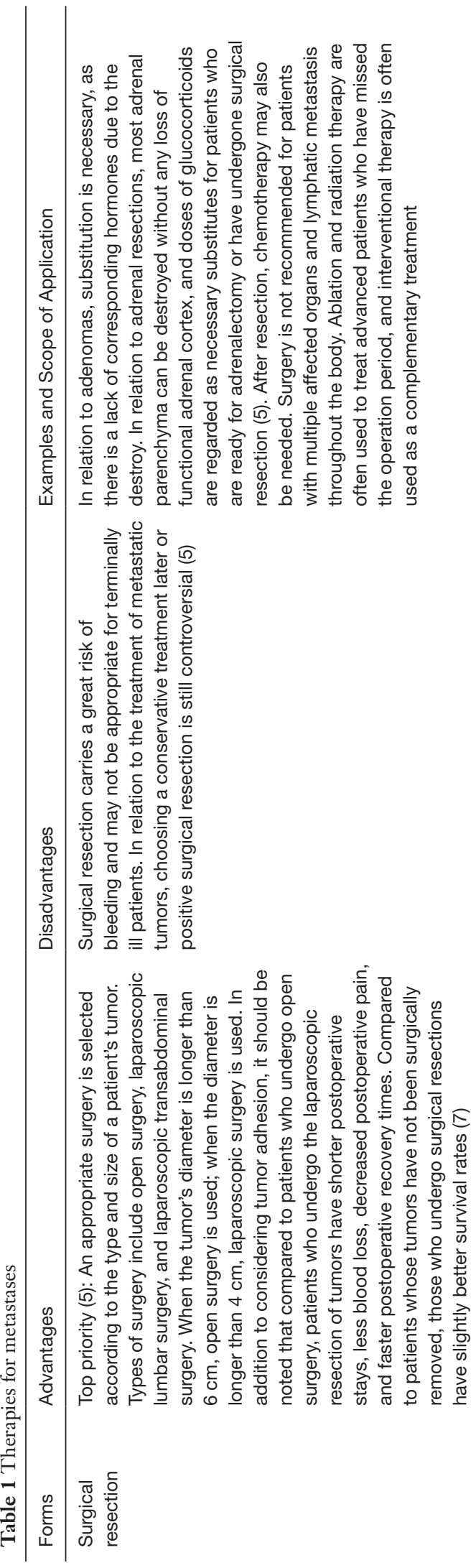

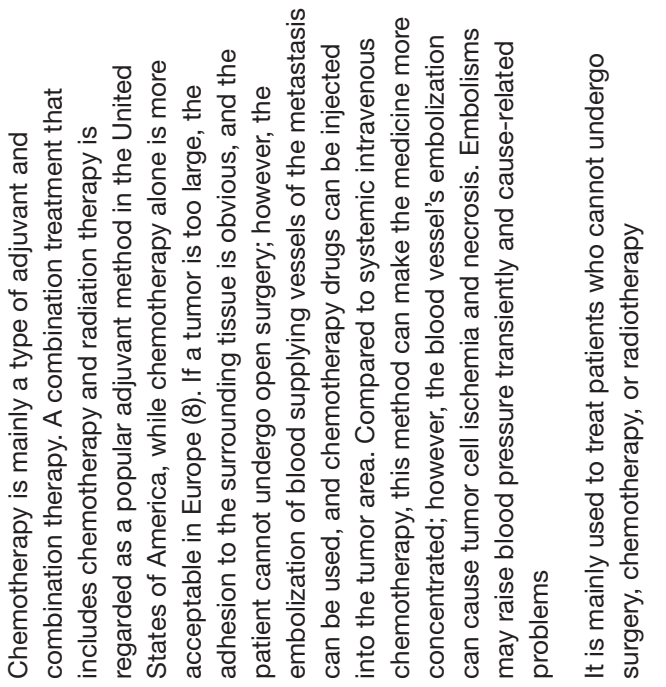
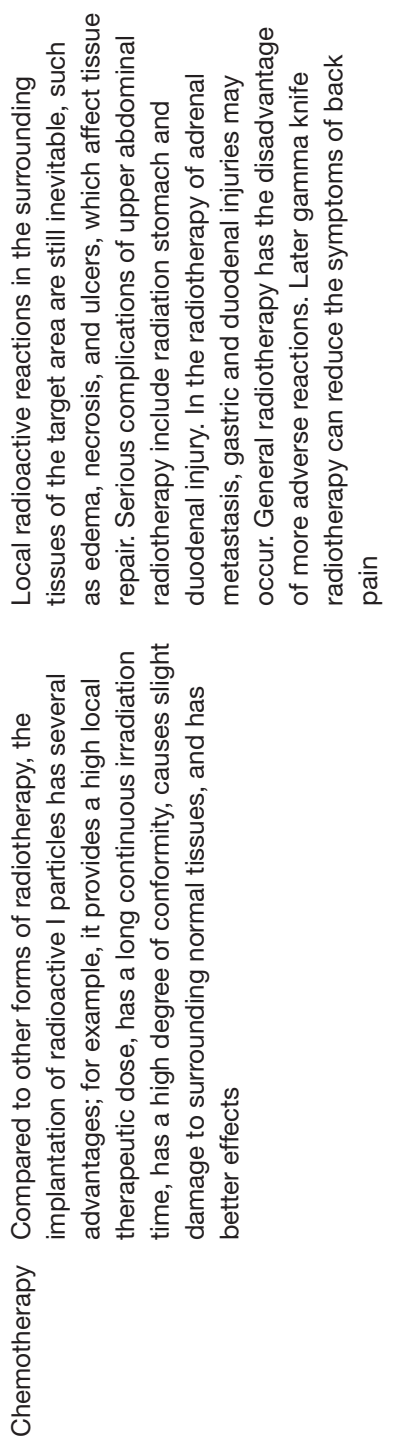

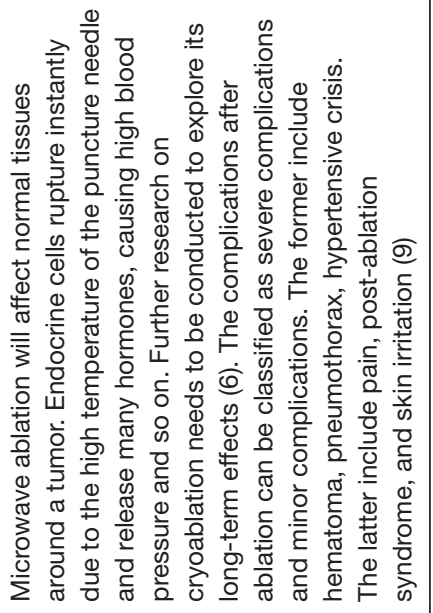

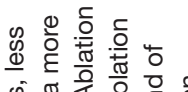

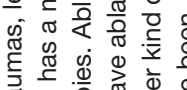

密

离

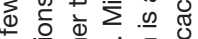

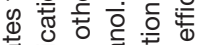

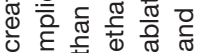

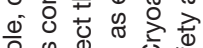

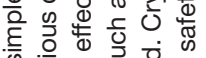

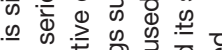

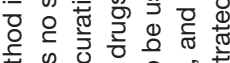

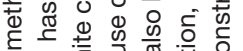

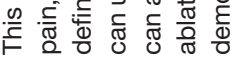

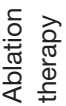




\section{Involvement of EMT in cancer metastasis}

As a result of EMT, cells show a loss of polarity, decreased adhesion, and enhanced migration, which are tumor cell characteristics. EMT has various molecular factors, phenotypic changes, and genetic changes in multi-step transmission (12). Conversely, metastatic lesions, such as cancer, cell proliferation, and proliferation, also require stroma to epithelial transition (13). In cancer, malignant epithelial cells acquire mesenchymal properties to promote migration, invasiveness, anti-apoptotic ability, and the production of extracellular matrix (ECM) components. Large amounts of genetic and epigenetic variation are also associated with type 3 EMT.

There is increasing evidence that micro ribonucleic acid (miRNA) is a key regulator of the EMT signaling pathway and TFs. Changes in miRNA expression affect the plan and metastasis of EMT. The regulation of miRNA expression in EMT has not yet been clearly identified; however, more and more signaling pathways and mechanisms have been explored and elucidated. The 3 encoding TFs of the Snail gene family (i.e., SNAI1, SNAI2, and SNAI3) perform unique functions. Their activation downregulates the expression of the epithelial gene and upregulates the expression of the mesenchymal gene. Various miRNAs regulate EMT by directly acting on the Snail family. Additionally, many genes promote or resist EMT through different targets and signaling pathways, affecting the migration and invasion of non-small-cell lung carcinoma (NSCLC) cells (14). For example, Snail is reported to promote EMT by activating transforming growth factorbeta (TGF- $\beta$ ), Smad, mitogen-activated protein kinase (MAPK), Wnt/Bcatenin, PI3/AKT, etc.

\section{Research progress in EMT}

\section{Gene and EMT}

EMT is regulated by genes greatly and here are some of the genes (Table 2) that matter.

\section{miRNAs and EMT}

Here we have listed some EMT-related miRNAs (Table 3).

The main methods by which miRNAs regulate EMT processes target TFs and components with epithelial or mesenchymal characteristics. Three families of TFs primarily control EMT; that is, ZEB (ZEB1/ZEB2), the zinc finger Snail (Snail/Slug), and the basic helix-loophelix (e.g., the Twist). To date, only a few studies have sought to examine the role of miRNAs in adrenal metastasis in lung cancer; however, similar research has shown that miRNAs have a controlling role in other kinds of cancer. Thus, we assumed that specific miRNAs would be found in adrenal metastasis and decided to make this the focus of our future research. The targeting of signaling pathways affected by miRNAs could help to define appropriate cancer treatments. Additionally, it could attenuate cancer progression in clinical treatments by preventing oncogenic miRNAs expression or by re-introducing miRNAs that can inhibit tumor metastasis (36).

\section{Signaling pathways and EMT}

In gene expression, signaling pathways (Table 4) in molecules function as connections and are synergistically involved in EMT.

As the key point of invasion and metastasis, EMT remarkably influences the development of various cancers, including lung cancer (55). In gene expression, the hallmark of EMT is the loss of specific markers for epithelial cell (e.g., E-cadherin, cytokeratin, and ZO-1), the gain of specific markers for mesenchymal cells (e.g., N-cadherin, vimentin, and FSP1), the rebuild of actin cytoskeletal, and the presence of adhesion and polarity between cells. Signaling pathways in EMT function as inhibitors of epithelial cell markers and promotors of mesenchymal cell markers. Usually, many signaling pathways work together to induce EMT.

To suppress the EMT process, signaling pathways must be blocked to bring about inhibition and reverse the EMT process. Sotetsuflavone can reverse EMT by blocking PI3K/ $\mathrm{AKT}$ and TNF- $\alpha / \mathrm{NF}-\kappa \mathrm{B}$ pathways, thus inhibiting the migration and invasion of NSCLC cells (43). Glaucocalyxin A can inhibit EMT by blocking the TGF- $\beta 1 / \operatorname{Smad} 2 / 3$ signaling pathway, holding back the metastasis of cancer (56).

\section{Cancer targeted therapy of EMT}

We found numerous examples of and projects examining the targeted therapy of various kinds of cancer, many of which could be applied to targeted symptoms (Table 5). However, the mechanism of epigenetic therapy is still not thoroughly understood, and its use should be carefully evaluated. Additionally, EMT mechanisms broaden cancer therapies.

\section{Prospects and challenges of EMT-targeted treatment}

EMT is closely related to all aspects of tumor metastasis. 
Table 2 Gene and EMT

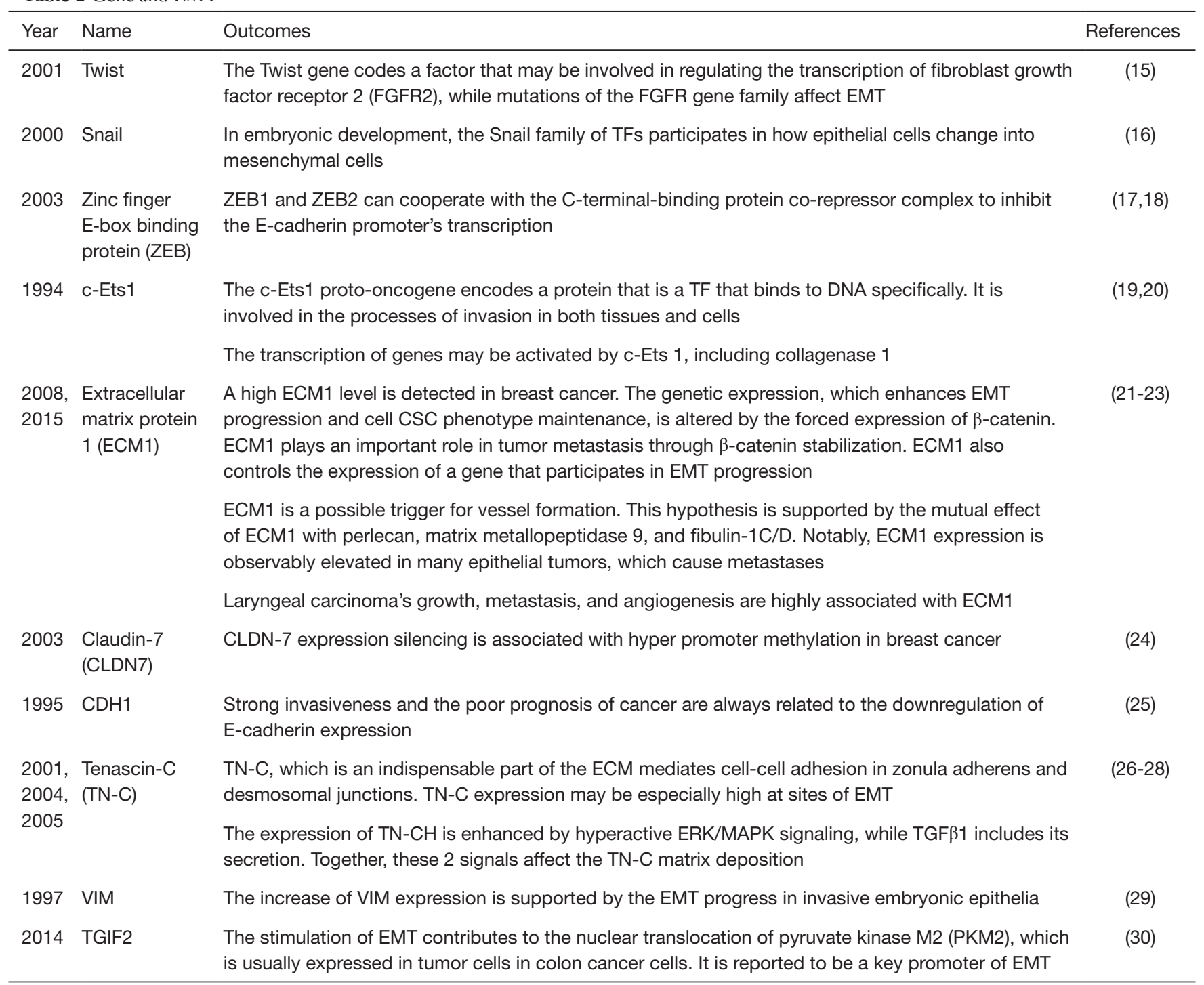

EMT, epithelial-mesenchymal transition.

As stated above, the design of a targeted intervention strategy for the key regulatory mechanism of EMT has recently become a popular area of research. One strategy to do this would be to block or reverse EMT, restoring epithelial cell features directly. However, research has shown that after the intervention of EMT, the sametime mesenchymal characteristics of cells in acquiring epithelial characteristics were often not fully reversed, and the reversal of EMT may promote the formation of large metastases (66). Under another strategy, the mesenchymal phenotype of metastatic tumor cells could be retained by a MET inhibitor to control metastasis progression (67). This strategy is promising, as it could convert invasive cancer cells into other types of cells to inhibit cancer metastasis (68). The potential value of EMT-targeted treatment for metastasis in cancer should be noted.

However, there are still many difficulties in this field. Extensive research needs to be conducted to identify the EMT mechanism. As the EMT mechanism is extremely complex, there is no reliable way to predict which key $\mathrm{TF}$ works in different tumors. Further, it is still unclear how TFs interact with each other in different tumor types to mediate EMT in tumor cells. Further, various intracellular and extracellular signaling pathways work together on tumor cells and activate the EMT process. However, it is still unknown how intracellular and extracellular signaling 
Table 3 miRNAs and EMT

\begin{tabular}{|c|c|c|c|}
\hline Targets & Name & Outcomes & References \\
\hline $\mathrm{CDH} 1$ & $\operatorname{miR}-9$ & $\begin{array}{l}\text { Research has shown that miR-9, which targets CDH1 straight, the E-cadherin-encoding messenger } \\
\text { RNA (mRNA), is overexpressed in breast cancer cells. MiR- } 9 \text { was identified as a pro-metastatic miRNA } \\
\text { that can downregulate E-cadherin expression, improving the motility and invasiveness of cancer cells } \\
\text { and activating } \beta \text {-catenin signaling, which is related to the promotion of the expression of VEGFA, thus } \\
\text { inducing tumor-associated angiogenesis. The MYC and MYCN oncoproteins, which target the mir- } 9-3 \\
\text { locus, can activate the expression of miR- } 9 \text { in tumor cells }\end{array}$ & (34) \\
\hline ZEB2 & $\operatorname{miR}-138$ & $\begin{array}{l}\text { MiR-138 has frequently been observed to be involved in a downregulation in head and neck squamous } \\
\text { cell carcinoma. MiR-138 controls EMT via } 3 \text { different pathways: (I) by directly acting on VIM mRNA and } \\
\text { regulating VIM expression at a post-transcriptional level; (II) by acting on transcriptional repressors (e.g., }\end{array}$ & (35) \\
\hline $\mathrm{EZH} 2$ & & ZEB2); and (III) by acting on the epigenetic regulator EZH2 & \\
\hline
\end{tabular}

EMT, epithelial-mesenchymal transition.

pathways regulate the EMT process in tumor cells.

It is also difficult to explore EMT-targeted treatment for a specific disease. EMT is known to be important in tumor cell metastasis; however, tumor metastasis is a multistage process in which EMT may play a different role. For example, due to the heterogeneity inherent in tumors, therapy for adrenal metastasis in lung cancer may differ. In clinical practice, we found that immunotherapy had a good therapeutic effect on all parts of patients' bodies, except for the adrenal gland. The adrenal gland may have immune privilege, which adds to the difficulty of exploring EMT-targeted treatments for adrenal metastasis. Thus, it is necessary to explore the EMT mechanism by focusing on one specific disease, such as adrenal metastasis in lung cancer.

\section{Methods}

This paper sought to elucidate the role and therapeutic significance of EMT in metastatic tumors. Thus, we approached the article from two aspects. After gaining a specific understanding of the mechanism, we conducted indepth research on the method and application of metastatic tumors and EMT. We then conducted further research on the related treatment of metastatic cancer by EMT in recent years.

First, "tumor metastasis" was used as the keyword to find relevant review articles to understand the familiar research methods and the difficulties of metastatic cancer. Also, secondary keywords (such as "detection" and "mechanism") were added to gain a specific understanding of metastatic tumors. Then, starting from EMT, we searched for relevant literature to understand its mechanism, research methods, and relevant clinical applications. We then cross-checked the literature using "EMT" and "metastatic tumors" as bidirectional keywords. In our search, we found many current therapies for various types of cancer metastasis that are related to EMT. We found the basic research context and utilization means of EMT in tumor therapy by undertaking a year-by-year summary. According to the types of cancers, the differences among different cancers were analyzed, as were the different EMT therapy effects. Most of the relevant pieces of literature examined in this paper were retrieved from the Web of Science and China National Knowledge Internet. The above logic is the mainline supplemented by searching and summarizing, the paper-related extension as a supplement to complete the review's writing. 
Table 4 Signaling pathways and EMT

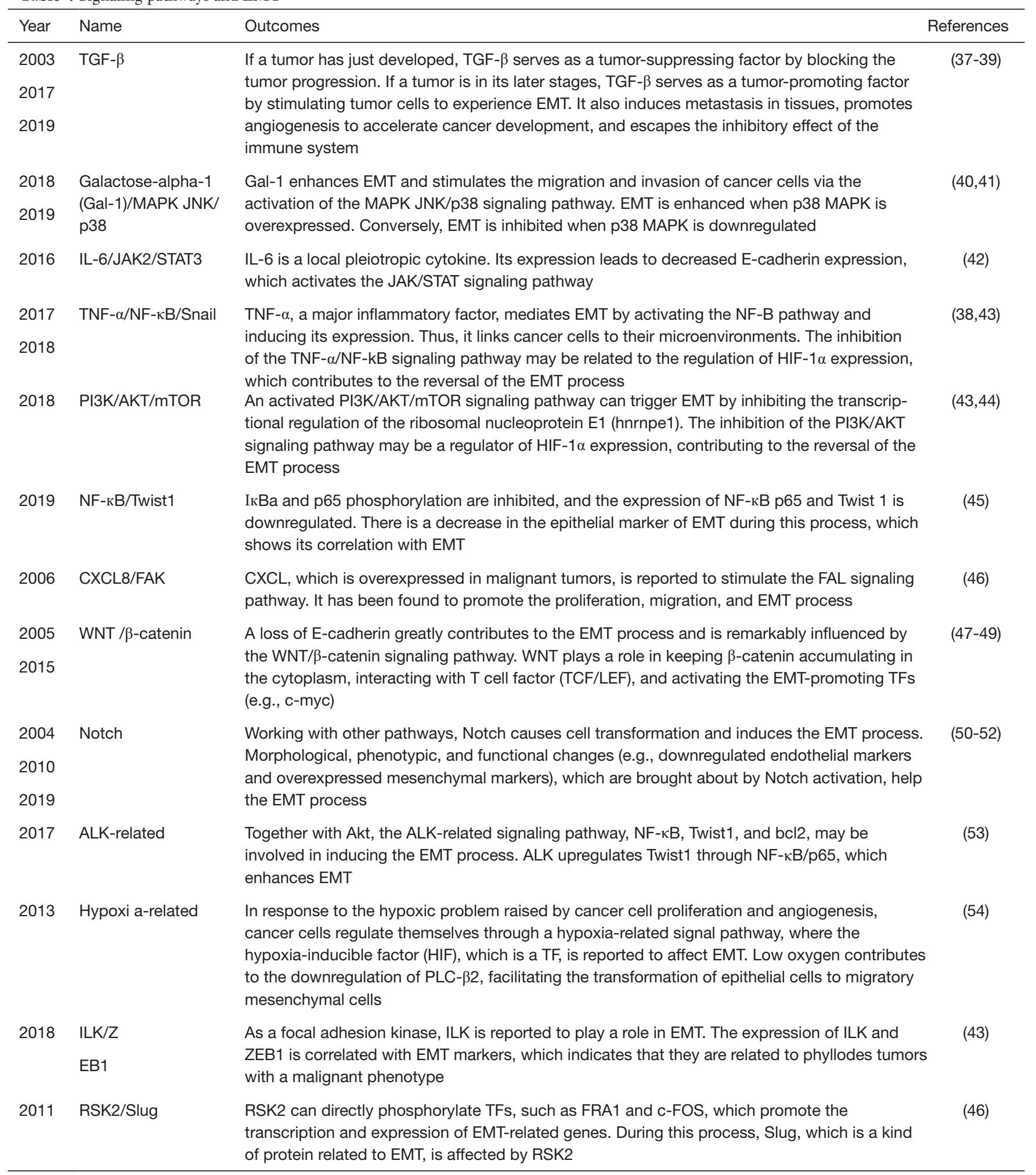


Table 5 Cancer targeted therapy of EMT

\begin{tabular}{|c|c|c|c|}
\hline Year & Name & Outcomes & References \\
\hline $\begin{array}{l}2010 \\
2018\end{array}$ & $\begin{array}{l}\text { DNMT } \\
\text { inhibitor }\end{array}$ & $\begin{array}{l}\text { DNA methyltransferases (DNMTs) can catalyze aberrant DNA methylation at the 5-position of cytosine } \\
\text { and thus assume an important role in silencing tumor-suppressing genes. DNMT inhibitors can indirectly } \\
\text { make tumor-suppressing genes work. For example, the DNMT inhibitor } 5 \text {-nitrocytidyl can restore the } \\
\text { expression of specific mir- } 200 \text { in epithelial cells, which makes cancer stem cells more sensitive to } \\
\text { traditional differentiation-induced therapies }\end{array}$ & $(61,62)$ \\
\hline 2004 & $\begin{array}{l}\text { Cytidine } \\
5 \text { - nitrogen }\end{array}$ & $\begin{array}{l}\text { The treatment of breast cancer cells with mda-mb-435s by } 5 \text {-cytidine can restore E-cadherin expression } \\
\text { and suppress tumor growth and metastasis }\end{array}$ & (63) \\
\hline 2020 & $\begin{array}{l}\text { Histone } \\
\text { deacetylase } \\
\text { (HDAC) } \\
\text { inhibitor }\end{array}$ & $\begin{array}{l}\text { HDAC inhibitors have been shown to have a significant effect on the treatment of some tumors. They } \\
\text { can target inflammatory processes by immune-modulatory compounds and greatly improve the } \\
\text { efficiency of cell reprogramming. For example, the HDAC inhibitor butyrate can induce the stagnation } \\
\text { of the tumor cell cycle and improve the cell-cell adhesion via the activation of G9a, Parnate (LSD1), and } \\
\mathrm{LiCl} \text { (GSK3), and the reduction of genomic methylation }\end{array}$ & (64) \\
\hline 2004 & $\begin{array}{l}\text { mTORC } \\
\text { inhibitor }\end{array}$ & $\begin{array}{l}\text { Research has shown that activity-elevated mTORC1 and mTORC2 has a role in controlling EMT and the } \\
\text { metastasis of CRC. Additionally, the mutual regulation of mTORC1, which inhibits the expression of both } \\
\text { mTORC1/mTORC2, can abolish their ability to impede both cell proliferation and migration throughout } \\
\text { aberrant metabolic pathways. Further, "Rapalink," a third-generation inhibitor of mTOR, can be } \\
\text { combined with an ATP-binding inhibitor and abolish the ability of mTORC1 }\end{array}$ & (65) \\
\hline
\end{tabular}

EMT, epithelial-mesenchymal transition.

\section{Discussion}

In this paper, we reorganized the literature about molecules linked to EMT in cancer metastasis. The studies examined in this review used cell experiments, animal experiments, biological information analysis technologies, and other reliable methods to explore cancer metastasis's molecular mechanisms, which are based on related genes, miRNAs, proteins, and pathways. However, it should be noted that current treatments are still in their infancy, and an EMTtargeted treatment is still an ideal concept. Most of the research studies identified in this paper were limited to a single view and ignored any connection to genes, miRNAs, proteins, and biological function. However, a clear connection between microcosmic and macroscopic functions could be revealed to map the molecular changes to the corresponding changes in clinical symptoms. Further, the relationship among related genes should be explored to determine the holistic generality among them.

Despite its many challenges and difficulties, such as regulating EMT's multifactorial process, EMT-targeted treatment is a promising treatment for metastasis in cancer. Future research could eliminate these limitations and build a bridge between microcosmic and macroscopic functions, enabling metastasizing cancers to be more accurately detected and treated. With bioinformatic evidence, the study of the prognosis of cancer metastasis may be realized.

\section{Conclusions}

As we described in this paper, EMT appears to promote the malignancy and metastasis of epithelial tumors, including lung cancer. Many studies have shown that inhibiting EMT 
suppresses cancer metastasis, which appears to prove the correlation between EMT and cancer metastasis. Two promising strategies to prevent cancer metastasis have been put forward to block or reverse EMT in metastasizing cancers. Thus, EMT-targeted treatment is a novel and promising therapy in the treatment of cancer. However, there are still many difficulties in this field, including those related to its complexity and diversity. We are convinced that future research will clearly identify the mechanism of EMT in cancer metastasis and improve the EMTtargeted treatments that can be used to intervene in cancer metastasis.

\section{Acknowledgments}

Funding: This study was supported in part by a grant from the National Undergraduate Training Program for Innovation and Entrepreneurship, National Natural Science Foundation of China (81802255), Young Talents in Shanghai (2019QNBJ), 'Dream Tutor' Outstanding Young Talents Program (fkyq1901), Clinical Research Project of Shanghai Pulmonary Hospital (fk18005), Key Discipline in 2019 (oncology), Project of Shanghai Municipal Science and Technology Commission (Project of Municipal Science and Technology Commission), and Scientific research project of Shanghai Pulmonary Hospital (fkcx1903).

\section{Footnote}

Reporting Checklist: The authors have completed the Narrative Review reporting checklist. Available at http:// dx.doi.org/10.21037/atm-20-7002

Peer Review File: Available at http://dx.doi.org/10.21037/ atm-20-7002

Conflicts of Interest: All authors have completed the ICMJE uniform disclosure form (available at http://dx.doi. org/10.21037/atm-20-7002). The authors have no conflicts of interest to declare.

Ethical Statement: The authors are accountable for all aspects of the work in ensuring that questions related to the accuracy or integrity of any part of the work are appropriately investigated and resolved.

Open Access Statement: This is an Open Access article distributed in accordance with the Creative Commons
Attribution-NonCommercial-NoDerivs 4.0 International License (CC BY-NC-ND 4.0), which permits the noncommercial replication and distribution of the article with the strict proviso that no changes or edits are made and the original work is properly cited (including links to both the formal publication through the relevant DOI and the license). See: https://creativecommons.org/licenses/by-nc-nd/4.0/.

\section{References}

1. Suhail Y, Cain MP, Vanaja K, et al. Systems Biology of Cancer Metastasis. Cell Syst 2019;9:109-27.

2. Valastyan S, Weinberg RA. Tumor metastasis: molecular insights and evolving paradigms. Cell 2011;147:275-92.

3. Thiery JP, Acloque H, Huang RY, et al. Epithelialmesenchymal transitions in development and disease. Cell 2009;139:871-90.

4. Qiu M, Tian XJ, Ma LL, et al. Multiple primary neoplasms with renal neurilemmoma:a case report and literature review. Beijing Da Xue Xue Bao Yi Xue Ban 2015;47:714-7.

5. Sancho JJ, Triponez F, Montet X, et al. Surgical management of adrenal metastases. Langenbecks Arch Surg 2012;397:179-94.

6. Uberoi J, Munver R. Surgical management of metastases to the adrenal gland: Open, laparoscopic, and ablative approaches. Curr Urol Rep 2009;10:67-72.

7. Lam KY, Lo CY. Metastatic tumours of the adrenal glands: a 30-year experience in a teaching hospital. Clin Endocrinol (Oxf) 2002;56:95-101.

8. Smaglo BG, Pishvaian MJ. Postresection chemotherapy for pancreatic cancer. Cancer J 2012;18:614-23.

9. Botsa EI,Thanou IL, Papatheodoropoulou AT, et al. Thermal Ablation in the Management of Adrenal Metastasis Originating from Non-small Cell Lung Cancer: A 5-year Single-center Experience. Chin Med J (Engl) 2017;130:2027-32.

10. Shumarova SY. Management of isolated adrenal metastases. Khirurgiia (Sofiia) 2016;82:87-96.

11. Steven R. Goodman, Medical Cell Biology (Third Edition) 2008;227-48.

12. Thiery JP. Epithelial-mesenchymal transitions in tumour. Nat Rev Cancer 2002;2:442-54.

13. Yang J, Weinberg RA. Epithelial-mesenchymal transition: at the crossroads of development and tumor metastasis. Dev Cell 2008;14:818-29.

14. Wu SG, Chang TH, Liu YN, et al. MicroRNA in Lung Cancer Metastasis. Cancers (Basel) 2019;11:265. 


\section{Page 10 of 12}

15. Bloch-Zupan A, Hunter N, Manthey A, et al. R-twist gene expression during rat palatogenesis. Int J Dev Biol 2001;45:397-404.

16. Cano A, Pérez-Moreno MA, Rodrigo I, et al. The transcription factor snail controls epithelial-mesenchymal transitions by repressing E-cadherin expression. Nat Cell Biol 2000;2:76-83.

17. Vandenbunder B, Queva C, Desbiens X, et al. Expression of the transcription factor c-Ets1 correlates with the occurrence of invasive processes during normal and pathological development. Invasion Metastasis 19941995;14:198-209.

18. Vandenbunder B, Wernert N, Stehelin D. Does the c-ets 1 oncogene participate in the regulation of tumor angiogenesis? Arch Inst Pasteur Tunis 1994;71:493-509.

19. Shi Y, Sawada J, Sui G, et al. Coordinated histone modifications mediated by a CtBP co-repressor complex . Nature 2003;422:735-8.

20. van Grunsven LA, Michiels C, Van de Putte T, et al. Interaction between Smad-interacting protein-1 and the corepressor C-terminal binding protein is dispensable for transcriptional repression of E-cadherin. J Biol Chem 2003;278:26135-45.

21. Lee KM, Nam K, Oh S, et al. ECM1 regulates tumor metastasis and CSC-like property through stabilization of $\beta$-catenin. Oncogene 2015;34:6055-65.

22. Sercu S, Zhang L, Merregaert J. The extracellular matrix protein 1: its molecular interaction and implication in tumor progression. Cancer Invest 2008;26:375-84.

23. Han Z, Lin GJ, Chi FL, et al. The relationship between the extracellular matrix and the angiogenesis and metastasis of laryngeal carcinoma. ORL J Otorhinolaryngol Relat Spec 2008;70:352-8.

24. Kominsky SL, Argani P, Korz D, et al. Loss of the tight junction protein claudin-7 correlates with histological grade in both ductal carcinoma in situ and invasive ductal carcinoma of the breast. Oncogene 2003;22:2021-33.

25. Berx G, Staes K, van Hengel J, et al. Cloning and characterization of the human invasion suppressor gene E-cadherin (CDH1). Genomics 1995;26:281-9.

26. Maschler S, Grunert S, Danielopol A, et al. Enhanced tenascin-C expression and matrix deposition during Ras/ TGF-beta-induced progression of mammary tumor cells. Oncogene 2004;23:3622-33.

27. Beiter K, Hiendlmeyer E, Brabletz T, et al. Beta-Catenin regulates the expression of tenascin-C in human colorectal tumors. Oncogene 2005;24:8200-4.

28. Dandachi N, Hauser-Kronberger C, Moré E, et al. Co- expression of tenascin-C and vimentin in human breast cancer cells indicates phenotypic transdifferentiation during tumour progression: correlation with histopathological parameters, hormone receptors, and oncoproteins. J Pathol 2001;193:181-9.

29. Pulyaeva H, Bueno J, Polette M, et al. MT1-MMP correlates with MMP-2 activation potential seen after epithelial to mesenchymal transition in human breast carcinoma cells. Clin Exp Metastasis 1997;15:111-20.

30. Hamabe A, Konno M, Tanuma N, et al. Role of pyruvate kinase $\mathrm{M} 2$ in transcriptional regulation leading to epithelial-mesenchymal transition. Proc Natl Acad Sci U S A 2014;111:15526-31.

31. Gregory PA, Bert AG, Paterson EL, et al. The miR-200 family and miR-205 regulate epithelial to mesenchymal transition by targeting ZEB1 and SIP1. Nat Cell Biol 2008;10:593-601.

32. Ru P, Steele R, Newhall P, et al. miRNA-29b suppresses prostate cancer metastasis by regulating epithelialmesenchymal transition signaling. Mol Cancer Ther 2012;11:1166-73.

33. Zhang J, Zhang H, Liu J, et al. miR-30 inhibits TGF$\beta 1$-induced epithelial-to-mesenchymal transition in hepatocyte by targeting Snail1. Biochem Biophys Res Commun 2012;417:1100-5.

34. Ma L, Young J, Prabhala H, et al. miR-9, a MYC/MYCNactivated microRNA, regulates E-cadherin and cancer metastasis. Nat Cell Biol 2010;12:247-56.

35. Liu X, Wang C, Chen Z, et al. MicroRNA-138 suppresses epithelial-mesenchymal transition in squamous cell carcinoma cell lines. Biochem J 2011;440:23-31.

36. Lamouille S, Subramanyam D, Blelloch R, et al. Regulation of epithelial-mesenchymal and mesenchymalepithelial transitions by microRNAs. Curr Opin Cell Biol 2013;25:200-7.

37. Peinado H, Quintanilla M, Cano A. Transforming growth factor beta-1 induces snail transcription factor in epithelial cell lines: mechanisms for epithelial mesenchymal transitions. J Biol Chem 2003;278:21113-23.

38. Li H, Zhong A, Li S, et al. The integrated pathway of TGF $\beta /$ Snail with $\mathrm{TNF} \alpha / \mathrm{NF} \kappa \mathrm{B}$ may facilitate the tumorstroma interaction in the EMT process and colorectal cancer prognosis. Sci Rep 2017;7:4915.

39. Hao Y, Baker D, Ten Dijke P. TGF- $\beta$-Mediated EpithelialMesenchymal Transition and Cancer Metastasis. Int J Mol Sci 2019;20:2767.

40. Zhu J, Zheng Y, Zhang H, et al. Galectin-1 induces metastasis and epithelial-mesenchymal transition (EMT) 
in human ovarian cancer cells via activation of the MAPK JNK/p38 signalling pathway. Am J Transl Res 2019;11:3862-78.

41. Xu M, Wang S, Wang Y, et al. Role of p38 $\gamma$ MAPK in regulation of EMT and cancer stem cells. Biochim Biophys Acta Mol Basis Dis 2018;1864:3605-17.

42. Xiao J, Gong Y, Chen Y, et al. IL-6 promotes epithelial-tomesenchymal transition of human peritoneal mesothelial cells possibly through the JAK2/STAT3 signaling pathway. Am J Physiol Renal Physiol 2017;313:F310-8.

43. Wang S, Yan Y, Cheng Z, et al. Sotetsuflavone suppresses invasion and metastasis in non-small-cell lung cancer A549 cells by reversing EMT via the TNF- $\alpha / \mathrm{NF}-\kappa \mathrm{B}$ and PI3K/ AKT signaling pathway. Cell Death Discov 2018;4:26.

44. Liu J, Huang B, Xiu Z, et al. PI3K/Akt/HIF-1 $\alpha$ signaling pathway mediates HPV-16 oncoprotein-induced expression of EMT-related transcription factors in nonsmall cell lung cancer cells. J Cancer 2018;9:3456-66.

45. Liu Y, Liu L, Zhu F. Therapies targeting the signal pathways of pheochromocytoma and paraganglioma. Onco Targets Ther 2019;12:7227-41.

46. Asati V, Mahapatra DK, Bharti SK. PI3K/Akt/mTOR and Ras/Raf/MEK/ERK signaling pathways inhibitors as anticancer agents: Structural and pharmacological perspectives. Eur J Med Chem 2016;109:314-41.

47. Brabletz T, Jung A, Spaderna S, et al. Opinion: Migrating cancer stem cells - an integrated concept of malignant tumour progression. Nat Rev Cancer 2005;5:744-9.

48. Yook JI, Li XY, Ota I, et al. Wnt-dependent regulation of the E-cadherin repressor snail. J Biol Chem 2005;280:11740-8.

49. Ghahhari NM, Babashah S. Interplay between microRNAs and $\mathrm{WNT} / \beta$-catenin signalling pathway regulates epithelial-mesenchymal transition in cancer. Eur J Cancer 2015;51:1638-49.

50. Noseda M, McLean G, Niessen K, et al. Notch activation results in phenotypic and functional changes consistent with endothelial-tomesenchymal transformation. Circ Res 2004;94:910-7.

51. Donnem T, Andersen S, Al-Shibli K, et al. Prognostic impact of Notch ligands and receptors in nonsmall cell lung cancer: coexpression of Notch-1 and vascular endothelial growth factor-A predicts poor survival. Cancer 2010;116:5676-85.

52. Kar R, Jha NK, Jha SK, et al. A "NOTCH" Deeper into the Epithelial-To-Mesenchymal Transition (EMT) Program in Breast Cancer. Genes (Basel) 2019;10:961.

53. Inoue $H$, Hashimura M, Akiya M, et al. Functional role of ALK-related signal cascades on modulation of epithelial-mesenchymal transition and apoptosis in uterine carcinosarcoma. Mol Cancer 2017;16:37.

54. Taïeb D, Yang C, Delenne B, et al. First report of bilateral pheochromocytoma in the clinical spectrum of HIF2Arelated polycythemia-paraganglioma syndrome. J Clin Endocrinol Metab 2013;98:E908-13.

55. Dauphin M, Barbe C, Lemaire S, et al. Vimentin expression predicts the occurrence of metastases in non small cell lung carcinomas. Lung Cancer 2013;81:117-22.

56. Jiang $X$, Zhang Z, Song C, et al. Glaucocalyxin A reverses EMT and TGF- $\beta 1$-induced EMT by inhibiting TGF- $\beta 1 /$ Smad2/3 signaling pathway in osteosarcoma. Chem Biol Interact 2019;307:158-66.

57. Wiggins JF, Ruffino L, Kelnar K, et al. Development of a lung cancer therapeutic based on the tumor suppressor microRNA-34. Cancer Res 2010;70:5923-30.

58. Hosseinahli N, Aghapour M, Duijf PHG, et al. Treating cancer with microRNA replacement therapy: A literature review. J Cell Physiol 2018;233:5574-88.

59. Ceppi P, Mudduluru G, Kumarswamy R, et al. Loss of miR-200c expression induces an aggressive, invasive, and chemoresistant phenotype in nonsmall cell lung cancer. Mol Cancer Res 2010;8:1207-16.

60. Ma L, Reinhardt F, Pan E, et al. Therapeutic silencing of miR-10b inhibits metastasis in a mouse mammary tumor model. Nat Biotechnol 2010;28:341-7.

61. Nam JS, Ino Y, Kanai Y, et al. 5-aza-2'- deoxycytidine restores the E-cadherin system in E-cadherin-silenced cancer cells and reduces cancer metastasis. Clin Exp Metastasis 2004;21:49-56.

62. Zhou Z, Li HQ, Liu F. DNA Methyltransferase Inhibitors and their Therapeutic Potential. Curr Top Med Chem 2018;18:2448-57.

63. Yang J, Mani SA, Donaher JL, et al. Twist, a master regulator of morphogenesis, plays an essential role in tumor metastasis. Cell 2004;117:927-39.

64. Chen G, Guo Y, Li C, et al. Small Molecules that Promote Self-Renewal of Stem Cells and Somatic Cell Reprogramming. Stem Cell Rev Rep 2020;16:511-23.

65. Jhanwar-Uniyal M, Wainwright JV, Mohan AL, et al. Diverse signaling mechanisms of mTOR complexes: mTORC1 and mTORC2 in forming a formidable relationship. Adv Biol Regul 2019;72:51-62.

66. Feng YL, Chen DQ, Vaziri ND, et al. Small molecule inhibitors of epithelial-mesenchymal transition for the treatment of cancer and fibrosis. Med Res Rev 2020;40:54-78. 
Page 12 of 12

67. Aiello NM, Kang Y. Context-dependent EMT programs in cancer metastasis. J Exp Med 2019;216:1016-26.

68. Ishay-Ronen D, Diepenbruck M, Kalathur RKR, et al. Gain FatLose Metastasis: Converting Invasive Breast

Cite this article as: Cai Y, Wang B, Li B, Huang X, Guo H, Liu Y, Chen B, Zhao S, Wu S, Li W, Wang L, Jia K, Wang $\mathrm{H}$, Chen P, Jiang M, Tang X, Qi H, Dai C, Ye J, He Y. Collection on reports of molecules linked to epithelialmesenchymal transition in the process of treating metastasizing cancer: a narrative review. Ann Transl Med 2021;9(11):946. doi: 10.21037/atm-20-7002

\section{Cai et al. Molecules collection linked to EMT in cancer metastasis}

Cancer Cells into Adipocytes Inhibits Cancer Metastasis. Cancer Cell 2019;35:17-32.e6.

(English Language Editors: L. Huleatt and J. Chapnick) 